\title{
Development of thermotolerant isolates of Beauveria bassiana (Bals.-Criv.) Vuill. with ethyl methanesulfonate
}

\author{
Yanisa Wongwanich ${ }^{1}$, Payorm Cobelli², Duangkamon Boonchuay ${ }^{3}$, Teerada Wangsomboondee ${ }^{1 *}$ \\ ${ }^{1}$ Department of Botany, Faculty of Science, Chulalongkorn University, Bangkok 10330, Thailand \\ ${ }^{2}$ Rice Research and Development Division, Rice Department, Bangkok 10900, Thailand \\ ${ }^{3}$ Chainat Rice Research Center, Chainat 17000, Thailand
}

Vol. 57, No. 4: 338-346, 2017

DOI: 10.1515/jppr-2017-0046

Received: August 1, 2017

Accepted: November 6, 2017

*Corresponding address:

teerada.w@chula.ac.th

\begin{abstract}
Beauveria bassiana is an entomopathogenic fungus that is widely used in Thailand to control pest insects. However, the increasing temperature has influenced the insect control efficiency of the fungus. Therefore, determination of thermotolerant isolates of B. bassiana that can grow and remain pathogenic at higher temperatures than its current optimum temperature may be a better way to control pest insects in a high temperature environment. Three isolates of B. bassiana obtained from the Rice Department, Thailand were selected for mutagenesis using ethyl methanesulfonate (EMS) with subsequent screening at high temperatures $\left(33\right.$ and $35^{\circ} \mathrm{C}$ ). In addition, the recovery of fungal growth after exposure to a high temperature for a period of time (5-15 days) and then transferring to $25^{\circ} \mathrm{C}$ was evaluated. No isolates were found that grew at $35^{\circ} \mathrm{C}$ but one mutant isolate (BCNT002MT) produced larger diameter colonies and more spores than the corresponding wild type (WT) at $33^{\circ} \mathrm{C}$. Growth and spore production of the BCNT002MT isolate were greater than its WT when incubated at $25^{\circ} \mathrm{C}$ for 14 days following exposure to $33^{\circ} \mathrm{C}$ for 7 days. In addition, the spore germination level (\%) of BCNT002MT was significantly higher than its WT during culture at $25^{\circ} \mathrm{C}$ after prior exposure to $33^{\circ} \mathrm{C}$ for 5,10 and 15 days. The pathogenicity against the brown planthopper, Nilaparvata lugens (Stål), of this mutant isolate was also prominent.
\end{abstract}

Key words: Beauveria bassiana, brown planthopper, ethyl methanesulfonate (EMS), mutation, thermotolerance

\section{Introduction}

The entomopathogenic fungus Beauveria bassiana is used as a biological agent for controlling insect pests. The fungus has a reported optimum temperature of around $25^{\circ} \mathrm{C}$ for hyphal growth (Hallsworth and Magan 1999; Tefera and Pringle 2003), while the highest pathogenicity against Diatraea saccharalis was reported to be at $26^{\circ} \mathrm{C}$ (Svedese et al. 2013). Temperature, humidity and solar radiation are all important factors for fungal growth, germination and viability (Zimmermann 2007). Climate change has a serious impact on the environment, including drought and higher temperatures, which can affect the fungal pathogenicity by reducing activities of the fungus before contacting its host or by reducing fungal growth within the host (Zimmermann 2007). Moreover, prolonged exposure to the sun's rays reduces the fungal viability and its sporulation. For example, the pathogenicity and spore germination level of $B$. bassiana grown at an optimum temperature or in a shady environment was higher than those that grew at a higher temperature or exposed to the sun, even when they were the same isolate (Inglis et al. 1997).

The mean annual temperature of Thailand during the last 35 years (1981-2015) has increased from 26.7 to $27.5^{\circ} \mathrm{C}$ (The Thai Meteorological Department 2017). However, Thailand has experienced a long period of warm weather during the hottest time of the year (March to May), when temperatures usually reach up to $40^{\circ} \mathrm{C}$. The efficiency of $B$. bassiana to control the brown planthopper (BPH), Nilaparvata lugens, 
during the rice growing season has decreased with the increasing temperature. In central Thailand, the average temperatures in irrigated areas (December to June) during the last three years (2014-2016) were 28.0, 28.6 and $29.4^{\circ} \mathrm{C}$, respectively, while during the rainy season (July to November) they were $28.4,28.8$ and $28.6^{\circ} \mathrm{C}$, respectively. Krutmuang (2011) studied two strains of B. bassiana (BCC6241 and BCC2637) for killing BPH in Thailand $\left(28 \pm 2^{\circ} \mathrm{C}, 70-80 \%\right.$ relative humidity) and found only a $60-67 \%$ induced mortality in $\mathrm{BPH}$, representing a low control efficiency. One way to increase the efficiency of $B$. bassiana pathogenicity is to improve the fungal ability to grow and control insect development at high temperatures. Moist heat treatment and UV irradiation have been used to induce mutagenesis in $B$. bassiana, where the derived mutant B. bassiana produced more blastospores than its respective wild type (WT) at $35^{\circ} \mathrm{C}$ (Avanti et al. 2014). However, moist heat could degrade the spore germinating protein (Wang et al. 2012), which may then expose the germinating spores to DNA changes or germinating protein degradation. The UV induced mutagenesis of Saccharomyces cerevisiae showed a low percentage of mutation (Lawrence and Christensen 1976), which may result from the ability of self DNA repair.

A chemical mutagen that is widely used and has a good efficiency to induce mutagenesis in fungi is ethyl methanesulfonate (EMS). Typically, EMS induces base-pair substitution, changing GC to AT and AT to $\mathrm{CG}$, but sometimes EMS induces base-pair insertion or base-pair deletion (Sega 1984). Reports of EMS inducing mutagenesis in fungi include induced oxalic acid production in Metarhizium anisopliae (Leger 1999) and temperature-sensitive mutants in S. cerevisiae (Momose and Gregory 1998). In this study, EMS was used to induce thermotolerance of $B$. bassiana. The mutant isolates were screened up to $35^{\circ} \mathrm{C}$. Growth, sporulation, spore germination and pathogenicity of the selected mutant isolate were then evaluated.

\section{Materials and Methods}

\section{Fungal isolates and molecular identification}

Three isolates of B. bassiana (BCNT001 to BCNT003) were obtained from the Rice Department, Thailand (RDT). The identification of each isolate was confirmed using morphological (Humber 2005; Rehner et al. 2011) and molecular characteristics. Molecular identification of $B$. bassiana isolates was performed by PCR amplification of a specific region in the translation elongation factor 1 alpha (EF1- $\alpha)$ gene using the species-specific primer pair EFFO (5'-TCGACCTCGACGAGCAATACATACTG-3') and EFRO (5'-GATACGACGAAAAAAAATTTGC GCAG-3') as previously reported (Johny and Kyei-Poku 2014) (Bio Basic Canada Inc., Canada). Three other isolates of B. bassiana, one each from the Thailand Institute of Scientific and Technological Research (TISTR3617), National Science and Technology Development (BCC22355) and Department of Agricultural Extension (BDOAE001), Thailand, were used as positive controls, while three isolates of Metarhizium spp. (MNBKK037, MNBKK039 and MNBKK040) and Xanthomonas oryzae (BB2014-288 and BB2014-292 for pv. oryzae and BLS2014-5 for pv. oryzicola) were obtained from the RDT, and used as negative controls.

The mycelial preparation and DNA extraction were adapted and performed as previously described (Carneiro et al. 2008; Safavi 2010). All fungal isolates were grown in Sabouraud's Dextrose Broth (SDB) medium at $27^{\circ} \mathrm{C}$ for $4-7$ days with agitation at $120 \mathrm{rpm}$. Fungal mycelia were then collected using No. 1 Whatman filter paper and ground to a fine powder in liquid nitrogen. The powdered fungal mycelia were transferred to $1.5-\mathrm{ml}$ microtubes for DNA extraction in $450 \mu \mathrm{l}$ of TES [1.4 M NaCl, $20 \mathrm{mM}$ ethylenediaminetetraacetic acid (EDTA) and 0.1 M Tris- $\mathrm{HCl}, \mathrm{pH} 8.0$ ], $50 \mu \mathrm{l}$ of $20 \%$ $(\mathrm{w} / \mathrm{v})$ cetyltrimethylammonium bromide and $2 \mu \mathrm{l}$ of $\beta$-mercaptoethanol, mixing and incubating at $65^{\circ} \mathrm{C}$ for $90 \mathrm{~min}$. After that the tubes were centrifuged $\left(2,236 \times g, 4^{\circ} \mathrm{C}\right.$ for $\left.5 \mathrm{~min}\right)$, the supernatant was harvested and extracted with an equal volume of $25: 24: 1(\mathrm{v} / \mathrm{v} / \mathrm{v})$ phenol : chloroform : isoamyl alcohol. After phase separation by centrifugation $\left(2,236 \times g, 4^{\circ} \mathrm{C}\right.$ for $\left.5 \mathrm{~min}\right)$ the aqueous phase was harvested and extracted in the same manner with the exception that $24: 1(\mathrm{v} / \mathrm{v})$ chloroform : isoamyl alcohol was used. The DNA was precipitated from the aqueous layer by adding an equal volume of absolute isopropanol, centrifuged $\left(12,879 \times \mathrm{g}, 4^{\circ} \mathrm{C}\right.$ for $\left.5 \mathrm{~min}\right)$ and the pellet washed twice with $70 \%(\mathrm{v} / \mathrm{v})$ ethanol. The DNA pellet was then air dried and dissolved in $50 \mu \mathrm{TE}$ buffer $(10 \mathrm{mM}$ Tris- $\mathrm{HCl}$ and $1 \mathrm{mM}$ EDTA, $\mathrm{pH}$ 8.0). The quantity and quality of extracted DNA was measured using a Nanodrop spectrophotometer (ND-1000 Spectrophotometer, NanoDrop, USA).

The total volume of the PCR reaction (Johny and Kyei-Poku 2014) was $25 \mu \mathrm{l}$ containing $10 \mathrm{pM}$ of each primer, 1X PCR Master mix (Promega Corporation, USA) and $20 \mathrm{ng}$ genomic DNA. The PCR was thermocycled at $94^{\circ} \mathrm{C}$ for $3 \mathrm{~min}$, followed by 35 cycles at $94^{\circ} \mathrm{C}$ for $30 \mathrm{~s}, 60^{\circ} \mathrm{C}$ for $30 \mathrm{~s}$ and $72^{\circ} \mathrm{C}$ for $1 \mathrm{~min}$, and then a final step at $72^{\circ} \mathrm{C}$ for $10 \mathrm{~min}$. The products were resolved alongside low molecular weight size markers by electrophoresis in $1.5 \%(\mathrm{w} / \mathrm{v})$ agarose gels and visualized by Gel Doc 2000, Bio-Rad, USA. The PCR products were purified and then direct sequen- 
ced commercially (Bio Basic Inc., Canada). Consensus sequences were checked for homologues in the NCBI GenBank data base using the BLASTn algorithm, and aligned and analyzed using ClustalW software.

\section{Pathogenicity test}

Four isolates of B. bassiana (BCNT001 to BCNT003 and BDOAE001) were screened for their pathogenicity against BPH. Fungal spore suspensions of each isolate were prepared at $10^{9}$ spores $\cdot \mathrm{ml}^{-1}$ in $0.05 \%(\mathrm{w} / \mathrm{v})$ Tween 80 in distilled water. Fungal spores were sprayed onto 60 fourth to fifth instar nymphs of BPH as described by Li et al. (2014), and then the sprayed insects were released into cages that contained 15-days old TN1 rice cultivars. Control samples were sprayed with $0.05 \%$ (v/v) Tween 80. Dead BPH were collected and recorded daily for 14 days, from which the pathogenic efficiency of each B. bassiana isolate was calculated. Sample means were analyzed with Duncan's Multiple Range test (DMRT) at 95\% confidence interval by SPSS Statistics (ver. 17.0, Chicago, IL).

\section{Induced thermotolerance of Beauveria bassiana using EMS mutagenesis}

The three B. bassiana isolates (BCNT001, BCNT002 and BCNT003) were determined for inducing mutagenesis by using EMS, according to a method adapted from Ho and Ho (2015). These isolates were cultured on potato dextrose agar (PDA) at $25^{\circ} \mathrm{C}$ for 14 days, and then a spore suspension of each isolate was prepared at $10^{6}$ spores $\cdot \mathrm{ml}^{-1}$. Next, $100 \mu \mathrm{l}$ of 0.5 or $1.0 \%(\mathrm{v} / \mathrm{v})$ EMS was added $(0.5$ and $1.0 \%(\mathrm{v} / \mathrm{v})$ final concentration) into each $900 \mu \mathrm{l}$ spore suspension of each isolate in a microcentrifuge tube, or sodium phosphate buffer $\mathrm{pH} 7$ for the control, and then incubated at $30^{\circ} \mathrm{C}$ for $60 \mathrm{~min}$. The EMS-treated spore suspension and control treatments were spread on PDA and incubated at $25^{\circ} \mathrm{C}$ for 7 days. For each treatment, fungal colonies that grew on PDA were then sub-cultured on PDA at 31,33 and $35^{\circ} \mathrm{C}$ for 7 days. After that, colony diameters of the mutant and its respective WT isolates were measured and compared. The mean colony diameter was analyzed with a T-test at $95 \%$ confidence interval using the SPSS Statistics ver. 17.0 (Chicago, IL) software. Those EMS-treated colonies that generated a larger colony (diameter) than their respective WT at the highest temperature were selected for further analysis.

\section{DNA polymorphism test}

The colonies selected from the EMS mutagenesis and their respective WT isolates were screened for DNA polymorphism using the Random Amplified Poly- morphic DNA (RAPD) technique with four primers: OPA02 (5'-TGCCGAGCTG-3'), OPA03 (5'-AGT CAGCCAG-3'), OPA09 (5'-GGGTAACGCC-3') and OPA13 (5'-CAGCACCCAC-3'). The PCR reaction was performed as reported by Carneiro et al. (2008) in a total volume of $25 \mu \mathrm{l}$ containing $0.4 \mu \mathrm{M}$ of each primer, 1X PCR Master mix (Promega Corporation, USA) and $25 \mathrm{ng}$ genomic DNA, and thermocycled at $94^{\circ} \mathrm{C}$ for $15 \mathrm{~s}$, followed by 40 cycles at $94^{\circ} \mathrm{C}$ for $15 \mathrm{~s}, 36^{\circ} \mathrm{C}$ for $30 \mathrm{~s}$ and $72^{\circ} \mathrm{C}$ for $1 \mathrm{~min}$, and then a final $72^{\circ} \mathrm{C}$ for $7 \mathrm{~min}$. The products were resolved and visualized as above. The DNA band patterns obtained with each primer pair for each isolate was recorded.

\section{Characterization of thermotolerant Beauveria bassiana}

The EMS-treated B. bassiana [0.5 and 1.0\% (v/v) final concentration] that generated a colony diameter larger than their respective $\mathrm{WT}$ at 33 or $35^{\circ} \mathrm{C}$ were examined for their thermotolerant characteristics. In addition, a recovery test was performed to evaluate the growth characteristics of the mutant isolate during the reported optimum temperature after encountering a high temperature. To this end, the mutant and its respective WT were cultured on PDA at $33^{\circ} \mathrm{C}$ (the highest tolerant temperature) for 7 days and then incubated at $25^{\circ} \mathrm{C}$ for 14 days, whereupon the colony diameter and spore numbers of all the isolates were measured.

The level of fungal spore germination (\%) is an important determinant in the efficiency of killing the host insect by pathogenic fungi. Thus, the percentage spore germination was studied during growth at the optimum temperature $\left(25^{\circ} \mathrm{C}\right)$ after exposure to a high temperature $\left(33^{\circ} \mathrm{C}\right)$ for various periods of time $(5,10$ and 15 days). The number of germinated spores was counted. Then, the potato dextrose broth (PDB) flasks containing fungal spores were transferred from 33 to $25^{\circ} \mathrm{C}$ and the number of germinated spores was counted daily for 4 days. Spore germination percentages were calculated. Sample means were analyzed with T-test at 95\% confidence interval by SPSS Statistics (ver. 17.0, Chicago, IL).

\section{Pathogenicity of the EMS mutant isolate}

Comparison of pathogenicity between the mutant and respective $\mathrm{WT}$ isolates was performed according to $\mathrm{Li}$ et al. (2014) with minor adaptations, as in the pathogenicity test section above, with the exception of using spore suspensions at $10^{8}$ and $10^{9}$ spores $\cdot \mathrm{ml}^{-1}$. Dead $\mathrm{BPH}$ were collected and recorded daily for 14 days, from which the pathogenic efficiency of each isolate of B. bassiana was calculated. Sample means were analyzed with DMRT at 95\% confidence interval by SPSS Statistics (ver. 17.0, Chicago, IL). 


\section{Results}

\section{Molecular identification}

Verification of $B$. bassiana morphological identification was performed by PCR amplification with the species-specific EFFO and EFRO primer pair. The species-specific $307 \mathrm{bp}$ band amplified from the EF-1a gene for B. bassiana (Johny and Kyei-Poku 2014) was present in all isolates of $B$. bassiana that were used in this study. No PCR product appeared in the three isolates of either Metarhizium spp. or Xanthomonas oryzae (Fig. 1). DNA sequence analysis of all three B. bassiana isolates from the RDT (BCNT001 to 003) showed $100 \%$ nucleotide identity to B. bassiana (GenBank accession code KJ500423). Thus, the molecular identification result supported their morphological identification as B. bassiana.

\section{Pathogenicity test}

The pathogenicity of the three $B$. bassiana isolates from the RDT against BPH was evaluated in August 2016 $\left(31.5 \pm 1.2^{\circ} \mathrm{C}, 76.8 \%\right.$ relative humidity). Two isolates (BCNT002 and BCNT003) showed a greater efficiency to kill $\mathrm{BPH}$ than the isolate from the Department of Agricultural Extension (BDOAE001) that is promoted for controlling pest insects in Thailand's rice fields (Table 1). Then, threeisolates, BCNT001,BCNT002 andBCNT003, were chosen for inducing mutagenesis by EMS. However, several dead BPH were found in control samples without any mycelial growth detected on the insects.

\section{Induced thermotolerance in Beauveria bassiana using EMS mutagenesis}

Induced thermotolerance by EMS mutagenesis was evaluated in the three most pathogenic B. bassiana isolates (Table 2). Fungal growth after treatment with both $0.5 \%$ and $1 \%(\mathrm{v} / \mathrm{v})$ EMS was decreased by $25 \%$ compared to the control at 25 and $31^{\circ} \mathrm{C}$. No colonies were found at $35^{\circ} \mathrm{C}$ and only one EMS-treated colony [from BCNT002 treated with 0.5\% (v/v) EMS] was found to survive and generate a larger diameter colony than its respective WT at $33^{\circ} \mathrm{C}$. Even at $31^{\circ} \mathrm{C}$, although there were many surviving EMS-treated colonies, their respective WT isolates could grow equally well at this temperature (data not shown).

\section{DNA polymorphism test}

The Random Amplified Polymorphic DNA analysis of the selected EMS-treated isolate (BCNT002MT) and its respective $\mathrm{WT}$ isolate (BCNT002WT) presented different DNA band patterns (Fig. 2). DNA bands present in the WT but not in the EMS-treated isolate were 120 bp from primers OPA $02 \times$ OPA03 and 180 and $1,300 \mathrm{bp}$ from primers OPA0 $2 \times$ OPA09. On the other hand, DNA bands present in the mutant but not present in the WT isolate were 1,000 and 1,500 bp from primers OPA02 $\times$ OPA09, 600 and 1,000 bp from primers OPA03 $\times$ OPA09 and $160 \mathrm{bp}$ from primers OPA03 $\times$ OPA13. Thus, detectable changes in the DNA of B. bassiana occurred after the EMS treatment.

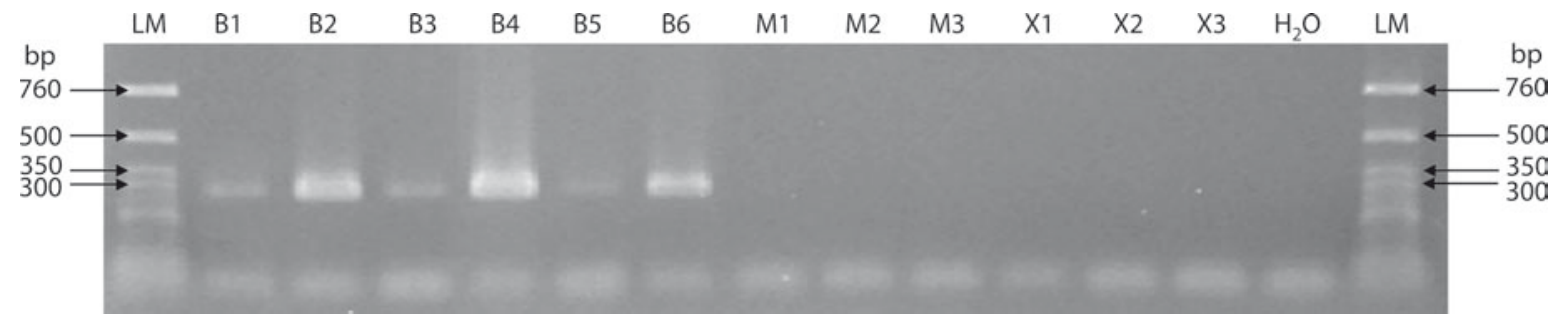

Fig. 1. Beauveria bassiana identification by PCR with the EF-1a species-specific primers EFFO and EFRO, showing the resolved PCR amplicon of 307 bp for B. bassiana. Lanes: LM - low molecular weight DNA ladder; B1-B6 - B. bassiana: B1 - BCNT001, B2 - BCNT002, B3 - BCNT003, B4 - TISTR3617, B5 - BCC22355 and B6 - BDOAE001; M1-M3 - Metarhizium spp.: M1 - MNBKK039, M2 - MNBKK040 and M3 - MNBKK037; X1-X2 - Xanthomonas oryzae pv. oryzae: X1 - BB2014-288 and X2 - BB2014-292; X3 - Xanthomonas oryzae pv. oryzicola: BLS2014-5 and $\mathrm{H}_{2} \mathrm{O}$. The gel shown is representative of three such amplifications

Table 1. Mortality of the brown planthopper (BPH) by Beauveria bassiana infection at 4 to 14 days after inoculation

\begin{tabular}{cccccc}
\hline \multirow{2}{*}{$\begin{array}{c}\text { Mortality of BPH } \\
{[\%]}\end{array}$} & BCNT001 & BCNT002 & BCNT003 & BDOAE001 & Tween 80 \\
\cline { 2 - 6 } & $20 \pm 3 \mathrm{~b}$ & $37 \pm 4 \mathrm{c}$ & $36 \pm 1 \mathrm{c}$ & $22 \pm 5 \mathrm{~b}$ & $0 \pm 0 \mathrm{a}$ \\
\hline
\end{tabular}

Data are shown as the mean \pm 1SD, derived from 3 replications. Means followed by different letters were significantly different according to the DMRT $(p<0.05)$ 
Table 2. Colony growth (\% of the control cells) of Beauveria bassiana after ethyl methanesulfonate (EMS) treatment and then incubated at $25,31,33$ and $35^{\circ} \mathrm{C}$ for 7 days

\begin{tabular}{|c|c|c|c|c|c|c|c|c|c|c|c|c|}
\hline \multirow{2}{*}{ Isolate } & \multicolumn{4}{|c|}{ Control } & \multicolumn{4}{|c|}{$0.5 \%(\mathrm{v} / \mathrm{v}) \mathrm{EMS}$} & \multicolumn{4}{|c|}{$1.0 \%(\mathrm{v} / \mathrm{v}) \mathrm{EMS}$} \\
\hline & $25^{\circ} \mathrm{C}$ & $31^{\circ} \mathrm{C}$ & $33^{\circ} \mathrm{C}$ & $35^{\circ} \mathrm{C}$ & $25^{\circ} \mathrm{C}$ & $31^{\circ} \mathrm{C}$ & $33^{\circ} \mathrm{C}$ & $35^{\circ} \mathrm{C}$ & $25^{\circ} \mathrm{C}$ & $31^{\circ} \mathrm{C}$ & $33^{\circ} \mathrm{C}$ & $35^{\circ} \mathrm{C}$ \\
\hline BCNT001 & 100 & 100 & 0 & 0 & 29 & 23 & 0 & 0 & 27 & 17 & 0 & 0 \\
\hline BCNT002 & 100 & 100 & 0 & 0 & 31 & 22 & 1 & 0 & 22 & 13 & 0 & 0 \\
\hline BCNT003 & 100 & 83 & 0 & 0 & 24 & 12 & 0 & 0 & 22 & 14 & 0 & 0 \\
\hline
\end{tabular}

Data are shown as the mean, derived from 3 replications for control while only one replication for 0.5 and $1.0 \%$ EMS mutations due to slow mycelial growth

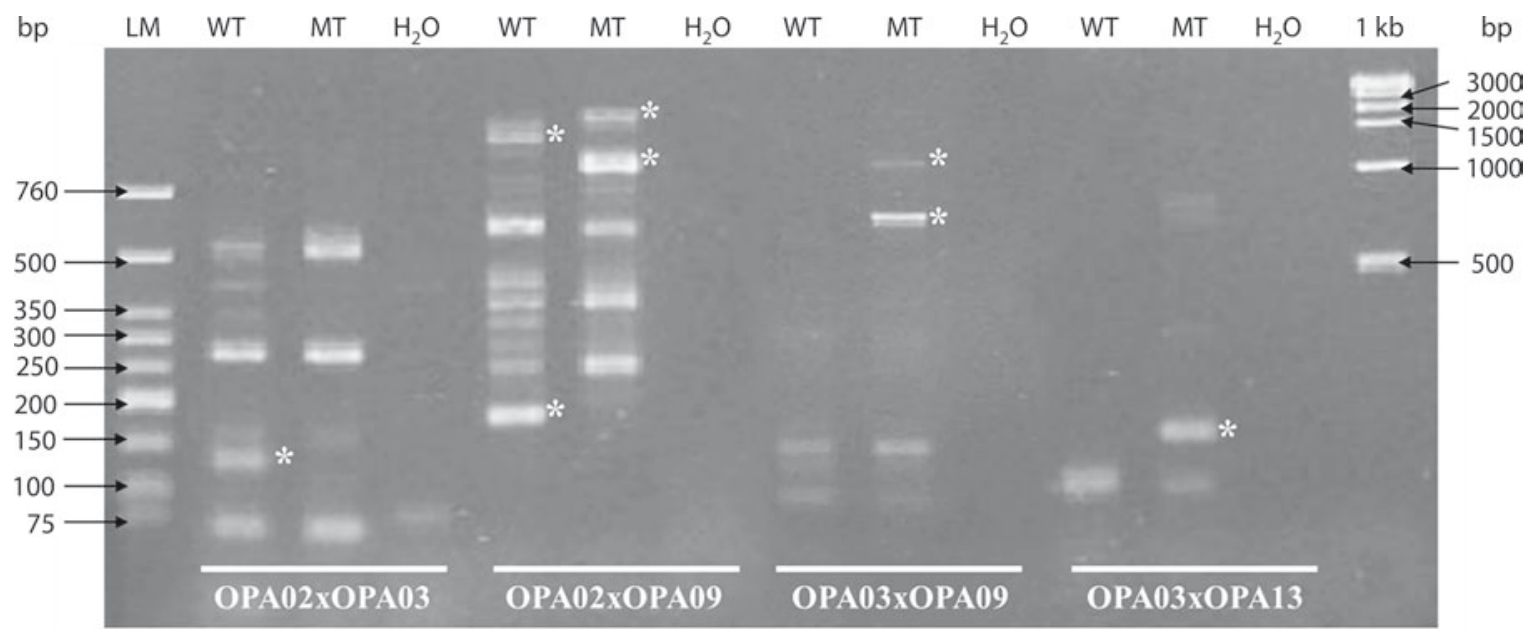

Fig. 2. The Random Amplified Polymorphic DNA (RAPD) results of the Beauveria bassiana isolates: BCNT002WT (WT), BCNT002MT (MT), and $\mathrm{H}_{2} \mathrm{O}$ (negative control). Lanes: (1) low molecular weight DNA ladder (LM), (2-4) OPA02 $\times$ OPA03, (5-7) OPA02 $\times$ OPA09, (8-10) OPA03 $\times$ OPA09, (11-13) OPA03 $\times$ OPA13 and (14) 1 kb ladder. DNA bands with asterisk $\left({ }^{*}\right)$ are of a different size between the wild type (WT) and mutant type (MT) isolates. Results shown are representative of three independent PCR RAPD assays

\section{Thermotolerant characteristics of Beauveria bassiana}

The thermotolerant B. bassiana isolate (BCNT002MT) grew significantly faster than the WT isolate when evaluated at $33^{\circ} \mathrm{C}$ (Fig. 3A). However, the colony growth rate of BCNT002MT $\left(0.07 \mathrm{~cm} \cdot \mathrm{d}^{-1}\right)$ at $33^{\circ} \mathrm{C}$ was very slow compared to being cultured at $25^{\circ} \mathrm{C}$ $\left(0.33 \mathrm{~cm} \cdot \mathrm{d}^{-1}\right)$. Therefore, a recovery test was performed by culturing the fungal mycelia at a high temperature $\left(33^{\circ} \mathrm{C}\right)$ for 7 days and then transferring them to the optimum growth temperature $\left(25^{\circ} \mathrm{C}\right)$. The mutant (BCNT002MT) recovered and grew better than the WT (BCNT002WT), where the colony diameter of the mutant isolate in the recovery test $(4.9 \pm 0.9 \mathrm{~cm})$ was close to that when cultured at $25^{\circ} \mathrm{C}(4.6 \pm 0.1 \mathrm{~cm})$, whereas the WT had smaller colonies in the recovery $(3.9 \pm 0.4 \mathrm{~cm})$ than at $25^{\circ} \mathrm{C}(4.5 \pm 0.3 \mathrm{~cm})$. In addition, a greater sporulation level (more spore formation) was evident for the mutant BCNT002MT after recovery from high temperature than its respective WT (Fig. 3B).

Spore culture at $33^{\circ} \mathrm{C}$ was conducted to assess the germination efficiency. However, no spore germination was found in both the mutant (BCNT002MT) and its WT (BCNT002MT) isolates when cultured at $33^{\circ} \mathrm{C}$ for
5,10 or 15 days (data not shown). Within the recovery test, spore germination at $25^{\circ} \mathrm{C}$ decreased with longer prior exposure times to the high temperature $\left(33^{\circ} \mathrm{C}\right)$. Spores cultured at $33^{\circ} \mathrm{C}$ for 5 days and then transferred to $25^{\circ} \mathrm{C}$ had a higher germination percentage than those incubated at $33^{\circ} \mathrm{C}$ for 10 or, especially, 15 days in both the mutant and WT isolates (Fig. 4). However, the spore germination percentage after transfer to $25^{\circ} \mathrm{C}$ was significantly greater in the mutant isolate than in the WT for all germination periods (Fig. 4).

\section{Pathogenicity test of the thermotolerant BCNT002MT isolate compared to its parental WT (BCNT002WT) isolate}

The bioassay to assess the pathogenicity of the thermotolerant mutant (BCNT002MT) isolate against $\mathrm{BPH}$ in comparison to its WT (BCNT002WT) isolate was performed in March $2017\left(35.0 \pm 2.5^{\circ} \mathrm{C}, 63.8 \%\right.$ relative humidity). The only significant difference between mutant and wild type isolates was the concentration $10^{9}$ spores $\cdot \mathrm{ml}^{-1}$. However, the BPH control efficiency was greater for the thermotolerant BCNT002MT isolate than the WT (BCNT002WT) at inoculation levels of both $10^{8}$ and $10^{9}$ spores $\cdot \mathrm{ml}^{-1}$ (Table 3 ). 
A

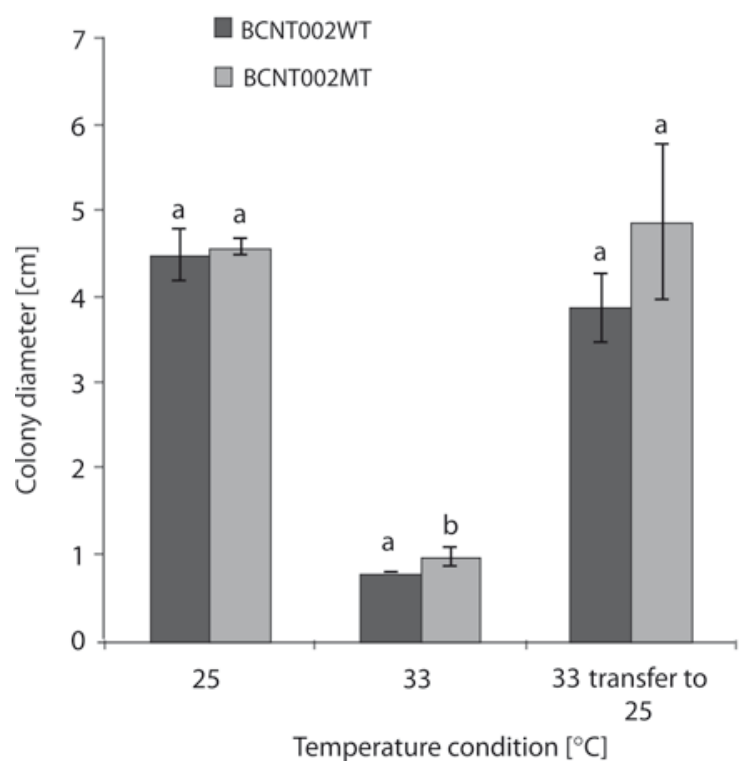

B

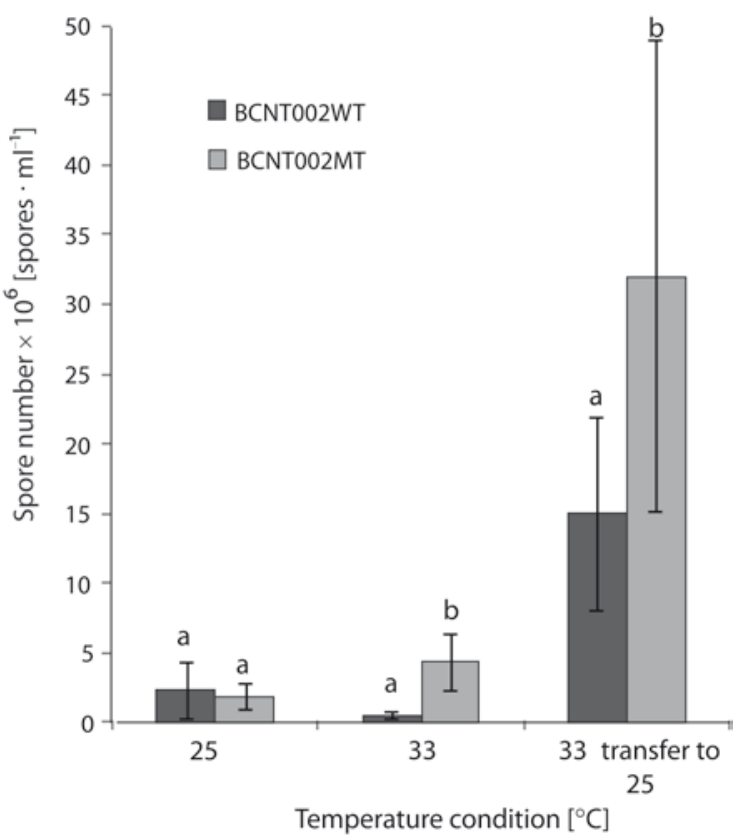

Fig. 3. The average $(A)$ colony diameter and $(B)$ number of spores for Beauveria bassiana isolates: $B C N T 002 W T$ and $B C N T 002 M T$ after incubation at $25^{\circ} \mathrm{C}$ and $33^{\circ} \mathrm{C}$ for 14 days, and at $33^{\circ} \mathrm{C}$ for 7 days and then transferred to $25^{\circ} \mathrm{C}$ for 14 days. Data are shown as the mean $\pm 1 S D$, derived from three repeats. Means with a different letter above them are significantly different $(p<0.05)$
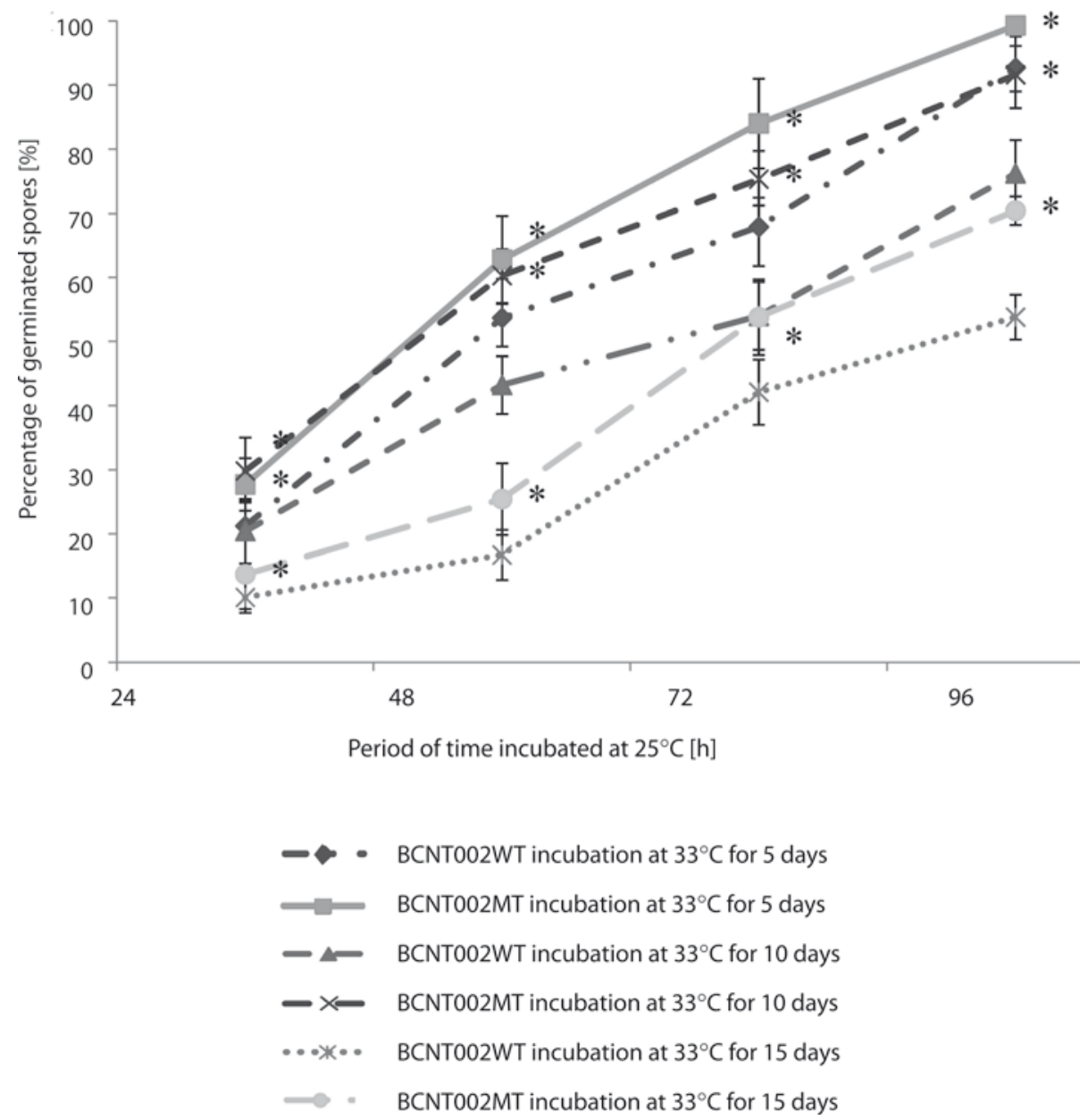

Fig. 4. The percentage of germinated spores when incubated at $25^{\circ} \mathrm{C}$ following prior incubation at $33^{\circ} \mathrm{C}$ for 5,10 and 15 days. Data are shown as the mean $\pm 1 S D$, derived from three repeats. Means with asterisk $\left.{ }^{*}\right)$ indicate a significant difference between the WT and mutant $(p<0.05)$ 
Table 3. Mortality (\%) of the brown planthopper (BPH) (after 14 days) induced by Beauveria bassiana infection inoculated with various spore concentrations

\begin{tabular}{cccc}
\hline \multirow{2}{*}{$\begin{array}{c}\text { Spore concentration } \\
{\left[\text { spores } \cdot \mathrm{ml}^{-1}\right]}\end{array}$} & BCNT002WT & Treatment & BCNT002MT \\
\cline { 2 - 4 } & $22 \pm 9 \mathrm{~b}$ & $30 \pm 12 \mathrm{~b}$ & $0 \pm 0 \mathrm{a}$ \\
\hline $10^{8}$ & $18 \pm 3 \mathrm{~B}$ & $46 \pm 8 \mathrm{C}$ & $0 \pm 0 \mathrm{~A}$ \\
\hline
\end{tabular}

Data are shown as the mean \pm 1SD, derived from three replications. Means followed by different letters were significantly different according to the DMRT $(p<0.05)$

\section{Discussion}

To support the morphological identification of the three isolates of $B$. bassiana from the RDT, PCR amplification of a $307 \mathrm{bp}$ fragment of the EF-1a gene was performed using the species-specific primers. The appropriate amplicon was detected in all three $B$. bassiana isolates from the RDT, plus the three control B. bassiana isolates, but not in the other six isolates from two other species, which agrees with a previous report (Johny and Kyei-Poku 2014). Moreover, DNA sequencing of the $307 \mathrm{bp}$ fragment of the EF-1a gene (GenBank accession codes JQ043235) supported the PCR result that three isolates from the RDT were B. bassiana. Therefore, the identification of these isolates as B. bassiana was accepted.

Two isolates (BCNT002 and BCNT003) revealed a higher pathogenicity under these conditions against $\mathrm{BPH}$ than the promoted isolate from the Department of Agricultural Extension (BDOAE001). These two isolates were recently isolated from infected $\mathrm{BPH}$ in rice fields, and so should have retained a high level of their virulence compared to repeatedly subcultured isolates (Ansari and Butt 2011). Improvement of these pathogenic isolates of B. bassiana, in terms of increased thermotolerance, was attempted by EMS mutagenesis with screening at the elevated culture temperatures of 33 and $35^{\circ} \mathrm{C}$. No colonies were found at $35^{\circ} \mathrm{C}$, but at $33^{\circ} \mathrm{C}$ one $0.5 \%(\mathrm{v} / \mathrm{v})$ EMS-treated colony (BCNT002MT) was found that could survive and generate a larger colony diameter than its respective WT (BCNT002WT). DNA polymorphism comparison between the BCNT002MT and BCNT002WT isolates showed different band patterns indicating changes in the DNA sequences. Normally EMS-induced mutations are evidenced by base-pair substitution (Sega 1984; Shiwa et al. 2012). However, whether the DNA band patterns presented in BCNT002MT but not in BCNT002WT (or vice versa) might be involved (causal rather than incidental) with thermotolerant genes in B. bassiana is unknown, but of course it does not have to be the case. Certainly, while whole genome analysis of EMS-treated Lotus japonicus revealed high single-nucleotide polymorphisms that were causal mutations for phenotypic changes (Mohd-Yusoff et al. 2015), we sampled only a small random fraction of the genome by this RAPD analysis.
The mutant isolate BCNT002MT produced a larger colony diameter and greater spore production than its corresponding WT isolate at $33^{\circ} \mathrm{C}$. Comparing the colony diameter and sporulation between the 25 and $33^{\circ} \mathrm{C}$ cultured conditions, both the mutant and WT isolates grew better at $25^{\circ} \mathrm{C}$ (optimum temperature) than at $33^{\circ} \mathrm{C}$, which is consistent with previous studies where high temperatures retarded or inhibited spore germination, hypha growth and sporulation of B. bassiana and also affected the fungal virulence (Shimazu 2004; Bugeme et al. 2008). Other studies have reported higher temperature tolerant isolates of $B$. bassiana up to $35^{\circ} \mathrm{C}$ (Shimazu 2004; Bugeme et al. 2008; Avanti et al. 2014). However, the optimal growth temperature of entomopathogenic fungi is likely to vary within a species depending on the geographic origin (OrduñoCruz et al. 2015) due to adaptation to local selection pressures, including the thermotolerant character.

In this study, the effect of fluctuating temperatures was tested. Exposure to high temperatures $\left(33^{\circ} \mathrm{C}\right)$ for a relatively short duration (5 to 15 days) had a lower inhibitory effect on growth as it was followed by recovery with culturing at the optimum temperature $\left(25^{\circ} \mathrm{C}\right)$. After treating the mutant isolate and its WT at the high temperature $\left(33^{\circ} \mathrm{C}\right)$ and transferring to the optimum temperature $\left(25^{\circ} \mathrm{C}\right)$, the mutant isolate revealed better growth and sporulation levels than its corresponding parental WT. The ability of B. bassiana to recover and grow after exposure to a high temperature has been reported before (Shimazu 2004).

No spore germination was found in all isolates at $33^{\circ} \mathrm{C}$ but after transferring to $25^{\circ} \mathrm{C}$, some spore germination was seen. Fungal spores typically need a specific temperature range for germination, and for B. bassiana the optimum temperature for germination was reported to be about $25^{\circ} \mathrm{C}$, depending on the fungal isolate. Thus, Qazzaz et al. (2015) reported that the optimum temperature range was $20-25^{\circ} \mathrm{C}$, whereas Bugeme et al. (2008) presented it as $25-30^{\circ} \mathrm{C}$, but at the non-optimal temperature the level of spore germination was low. Sivasankaran et al. (1998) reported that B. bassiana isolates require high levels of water activity for germination. This experiment showed that the higher temperature of $33^{\circ} \mathrm{C}$ significantly affected spore germination when culturing spores in a liquid media 
(and so a high water activity). In addition, the high temperature tolerance of $B$. bassiana depended on the fungal stage, with spores being more tolerant to the high temperature than hypha. In accordance, Shima$\mathrm{zu}$ (2004) reported that B. bassiana spores survived at high temperatures for a longer time than the hypha, which reflects that spores are better adapted to survive in high stress environments (Shimazu 2004; Liu et al. 2015). Interestingly, the mutant isolate of this study (BCNT002MT) produced a higher number of spores than the WT isolate, which could potentially promote spore survival. Moreover, non-optimal temperatures induced exogenous dormancy in asexual fungal spores as a response to the unfavorable conditions (Feofilova et al. 2012).

The level of spore germination (\%) of the BCNT 002MT isolate was significantly higher than the WT when transferred from $33^{\circ} \mathrm{C}$ and incubated at $25^{\circ} \mathrm{C}$. High temperatures normally decrease the viability of fungal spores (Zimmermann 2007), which explains why fewer spores germinated after incubating the fungal spores at $33^{\circ} \mathrm{C}$ for 15 days, than at 10 or 5 days, before being transferred to $25^{\circ} \mathrm{C}$. This is consistent with the report that exposure to a high temperature for a longer time caused a lower germination rate, and that at over $36^{\circ} \mathrm{C}$ no spores germinated (Shimazu 2004). Overall, the fungal radial growth, sporulation and spore germination level of the BCNT002MT mutant isolate were greater than the WT, suggesting that the mutant isolate is better adapted under these experimental conditions to fluctuating temperatures than the WT. However, the trade-offs and stability of this/ these trait(s) remain unknown.

The thermotolerant BCNT002MT mutant and its respective WT isolate were tested for their pathogenicity against nymphal stages of $\mathrm{BPH}$, where the mutant isolate caused higher insect mortality than the WT isolate at a spore inoculum of both $10^{8}$ and $10^{9}$ spores $\cdot \mathrm{ml}^{-1}$. Bugeme et al. (2008) reported that fungal virulence on insects was associated with the fungal isolate and temperature, where different isolates of $B$. bassiana resulted in a different mortality of tomato spider mites at different temperatures. For example, isolate ICIPE278 caused a higher mortality at $25^{\circ} \mathrm{C}$ than ICIPE279, but this was vice versa at $30^{\circ} \mathrm{C}$, where the mutant isolate adjusted itself better than the WT isolate under stable greenhouse conditions $\left(35.0 \pm 2.5^{\circ} \mathrm{C}\right)$. The efficiency of fungal pathogenicity is known to involve many factors, including spore germination efficiency, hyphal growth and sporulation (Zimmermann 2007).

The improved hyphal growth, sporulation and germination after confronting a high temperature of the mutant BCNT002MT isolate makes it a candidate for further study as a potential agent for Thai agriculturists to use for controlling insect pests in Thailand.
However, the trade-offs of such genetic changes and their stability under heterogeneous environmental conditions are unknown and require evaluation prior to mass rearing and release.

\section{Acknowledgements}

The authors wish to thank the RDT for fungal samples, $\mathrm{BPH}$ and support for conducting experiments and The Thai Meteorological Department for providing the average temperature information for central Thailand. The first author received financial support from the Chulalongkorn University Graduate Scholarship to commemorate the 72nd anniversary of His Majesty King Bhumibol Adulyadej.

\section{References}

Ansari M.A., Butt T.M. 2011. Effects of successive subculturing on stability, virulence, conidial yield, germination and shelf-life of entomopathogenic fungi. Journal of Applied Microbiology 110 (6): 1460-1469. DOI: 10.1111/j.1365-2672.2011.04994.x.

Avanti B., Balaraman K., Gopinath R. 2014. Development of higher temperature tolerant mutant of Beauveria bassiana and Verticillium lecanii. International Journal of Life Sciences Biotechnology and Pharma Research 3 (3): 109-112.

Bugeme D.M., Maniania N.K., Knapp M., Boga H.I. 2008. Effect of temperature on virulence of Beauveria bassiana and Metarhizium anisopliae isolates to Tetranychus evansi. Experimental and Applied Acarology 46 (1-4): 275-285. DOI: 10.1007/s10493-008-9179-1.

Carneiro A.A., Gomes E.A., Guimarães C.T., Fernandes F.T., Carneiro N.P., Cruz I. 2008. Molecular characterization and pathogenicity of isolates of Beauveria spp. to fall armyworm. Pesquisa Agropecuária Brasileira 43 (4): 513-520. DOI: http://dx.doi.org/ 10.1590/S0100-204X2008000400010

Feofilova E.P., Ivashechkin A.A., Alekhin A.I., Sergeeva Ya.E. 2012. Fungal spores: dormancy, germination, chemical composition, and role in biotechnology. Applied Biochemistry and Microbiology 48 (1): 1-11. DOI: 10.1134/ S0003683812010048

Hallsworth J.E., Magan N. 1999. Water and temperature relations of growth of the entomogenous fungi Beauveria bassiana, Metarhizium anisopliae, and Paecilomyces farinosus. Journal of Invertebrate Pathology 74 (3): 261-266. DOI: 10.1006/jipa. 1999.4883

Ho H.L., Ho K.F. 2015. Aspergillus brasiliensis for overproduction of xylanase in submerged fermentation through UV irradiation and chemicals mutagenesis. Journal of Advances in Biology \& Biotechnology 3 (3): 117-131. DOI: 10.9734/ JABB/2015/17274

Humber R.A. 2005. Entomopathogenic fungal identification. Available on: http://www.ars.usda.gov/ SP2UserFiles/ Place/80620510/APSwkshoprev.pdf

Inglis G.D., Johnson D.L., Goettel M.S. 1997. Effects of temperature and sunlight on mycosis (Beauveria bassiana) (Hyphomycetes: Sympodulosporae) of grasshoppers under field conditions. Environmental Entomology 26 (2): 400-409. DOI: https://doi.org/10.1093/ee/26.2.400

Johny S., Kyei-Poku G. 2014. A molecular tool for detection and tracking of a potential indigenous Beauveria bassiana strain for managing emerald ash borer populations in Canada. Journal of Invertebrate Pathology 122: 16-21. DOI: 10.1016/j.jip.2014.07.005. 
Krutmuang P. 2011. Brown planthopper (Nilaparvata lugens) and pest management in Thailand. In: Conference on International Research on Food Security, Natural Resource Management and Rural Development, University of Bonn, Germany, October 5-7, 2011. Available on: https://www.researchgate.net/publication/266893772 [Accessed: August 12, 2015]

Lawrence C.W., Christensen R.B. 1979. Ultraviolet-induced reversion of $c y c l$ alleles in radiation-sensitive strains of yeast III reu3 mutant strains. Genetics 92: 397-408.

Leger R.J., Nelson J.O., Screen S.E. 1999. The entomopathogenic fungus Metarhizium anisopliae alters ambient $\mathrm{pH}$, allowing extracellular protease production and activity. Microbiology 145 (1999): 2691-2699. DOI: 10.1099/00221287-145-10-2691

Li M., Li S., Xu A., Lin H., Chen D., Wang H. 2014. Selection of Beauveria isolates pathogenic to adults of Nilaparvata lugens. Journal of Insect Science 14 (32): 1-12. DOI: $10.1673 / 031.014 .32$

Liu H., Zhao X., Guo M., Liu H., Zheng Z. 2015. Growth and metabolism of Beauveria bassiana spores and mycelia. BMC Microbiology 15: 1-12. DOI: 10.1186/s12866-015-0592-4.

Mohd-Yusoff N.F., Ruperao P., Tomoyoshi N.E., Edwards D., Gresshoff P.M., Biswas B., Batley J. 2015. Scanning the effects of ethyl methanesulfonate on the whole genome of Lotus japonicus using second-generation sequencing analysis. G3 (Bethesda) 5 (4): 559-567. DOI: 10.1534/g3.114.014571

Momose H., Gregory K.F. 1998. Temperature-sensitive mutants of Saccharomyces cerevisiae variable in the methionine content of their protein. Applied and Environmental Microbiology 35 (4): 641-647.

Orduño-Cruz N., Guzmán-Franco A.W., Rodríguez-Leyva E., Alatorre-Rosas R., González-Hernández H., Mora-Aguilera G., Rodríguez-Maciel, J.C. 2015. In vitro selection of a fungal pathogen for use against Diaphorina citri. Biological Control 90: 6-15. DOI: http://dx.doi.org/10.1016/j. biocontrol.2015.05.010

Qazzaz F.O., Al-Masri M.I., Barakat R.M. 2015. Effectiveness of Beauveria bassiana native isolates in the biological control of the Mediterranean fruit fly (Ceratitis capitata). Advances in Entomology 3: 44-55. DOI: http://dx.doi.org/10.4236/ ae.2015.32006

Rehner S.A., Minnis A.M., Sung G., Luangsa-ard J.J., Devotto L., Humber R.A. 2011. Phylogeny and systematics of the anamorphic, entomopathogenic genus Beauveria. Mycologia 103 (5): 1055-1073. DOI: $10.3852 / 10-302$
Safavi S.A. 2010. Isolation, identification and pathogenicity assessment of a new isolate of entomopathogenic fungus, Beauveria bassiana in Iran. Journal of Plant Protection Research 50 (2): 158-163. DOI: https://doi.org/10.2478/ v10045-010-0027-z

Sega G.A. 1984. A review of the genetic effects of ethyl methanesulfonate. Mutation Research 134 (2-3): 113-142.

Shimazu M. 2004. Effects of temperature on growth of Beauveria bassiana F-263, a strain highly virulent to the Japanese pine sawyer, Monochamus alternatus, especially tolerance to high temperatures. Applied Entomology and Zoology 39 (3): 469-475. DOI: http://doi.org/10.1303/aez.2004.469

Shiwa Y., Fukushima-Tanaka S., Kasahara K., Horiuchi T., Yoshikawa H. 2012. Whole-genome profiling of a novel mutagenesis technique using proofreading-deficient DNA polymerase $\delta$. International Journal of Evolutionary Biology 2012: 860797. DOI:10.1155/2012/860797

Sivasankaran P., Eswaramoorthy S., David H. 1998. Influence of temperature and relative humidity on the growth, sporulation and pathogenicity of Beauveria bassiana. Journal of Biological Control 12: 71-75.

Svedese V.M., Lima E.Á.L.A., Porto A.L.F. 2013. Horizontal transmission and effect of the temperature in pathogenicity of Beauveria bassiana against Diatraea saccharalis (Lepidoptera: Crambidae). Brazilian Archives of Biology and Technology 56 (3): 413-419. DOI: http://dx.doi.org/10.1590/ S1516-89132013000300009

Tefera T., Pringle K. 2003. Germination, radial growth, and sporulation of Beauveria bassiana and Metarhizium anisopliae isolates and their virulence to Chilo partellus (Lepidoptera: Pyralidae) at different temperatures. Biocontrol Science and Technology 13 (7): 699-704. DOI: http://dx.doi. org/10.1080/0958315031000151756

The Thai Meteorological Department, Annual Mean Temperature in Thailand. 2017. Available on: https://www.tmd.go.th/ climate/climate.php?FileID =7 [Accessed: September 10, 2016]

Wang G., Paredes-Sabja D., Sarker M.R., Green C., Setlow P., Li Y.Q. 2012. Effects of wet heat treatment on the germination of individual spores of Clostridium perfringens. Journal of Applied Microbiology 113 (4): 824836. DOI: 10.1111/ j.1365-2672.2012. 05387.x.

Zimmermann G. 2007. Review on safety of the entomopathogenic fungi Beauveria bassiana and Beauveria brongniartii. Biocontrol Science and Technology 17 (6): 553-596. DOI: http://dx.doi.org/10.1080/09583150701309006 